\title{
Data Analysis and Reporting of the 150 Chevrolet Volts ARRA Demonstration Fleet
}

Richard "Barney" Carlson

July 2014

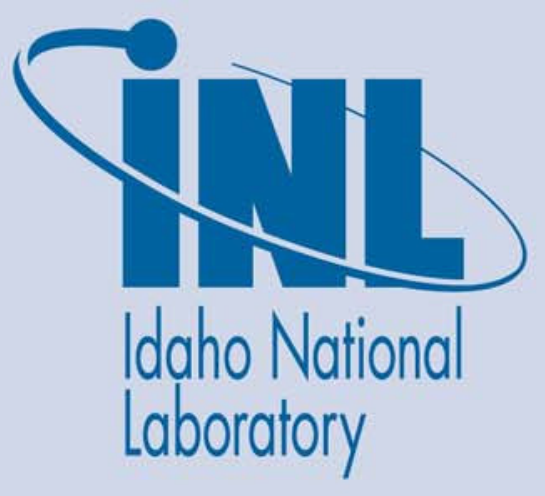

The INL is a U.S. Department of Energy National Laboratory operated by Battelle Energy Alliance 


\section{DISCLAIMER}

This information was prepared as an account of work sponsored by an agency of the U.S. Government. Neither the U.S. Government nor any agency thereof, nor any of their employees, makes any warranty, expressed or implied, or assumes any legal liability or responsibility for the accuracy, completeness, or usefulness, of any information, apparatus, product, or process disclosed, or represents that its use would not infringe privately owned rights. References herein to any specific commercial product, process, or service by trade name, trade mark, manufacturer, or otherwise, does not necessarily constitute or imply its endorsement, recommendation, or favoring by the U.S. Government or any agency thereof. The views and opinions of authors expressed herein do not necessarily state or reflect those of the U.S. Government or any agency thereof. 


\title{
Data Analysis and Reporting of the 150 Chevrolet Volts ARRA Demonstration Fleet
}

\author{
Richard "Barney" Carlson
}

July 2014

Idaho National Laboratory Idaho Falls, Idaho 83415

http://avt.inel.gov

Prepared for the

U.S. Department of Energy

Office of Nuclear Energy

Under DOE Idaho Operations Office

Contract DE-AC07-05ID14517 


\section{Data Analysis and Reporting of the 150 Chevrolet Volts ARRA Demonstration Fleet}

Idaho National Laboratory received driving and charging data from OnStar for 150 Chevrolet Volts that were collected from May 2011 through March 2014 as part of the ARRA Vehicle Demonstration. Idaho National Laboratory analyzed the data and published quarterly reports to http://avt.inel.gov/gmvehicledemo.shtml; these reports detailed the vehicle operational characteristics, fuel economy, electrical energy consumption, driving and charging utilization, driving style efficiency, and ambient temperature profiles.

From March 2011 through March 2014, the fleet of 150 Chevrolet Volts accumulated a total distance of 3.84 million miles over a total of 66,572 days of driving. Over the entire data collection period, the fleet average fuel economy was $67.5 \mathrm{mpg}$ and overall alternating current (AC) electrical energy consumption was $167 \mathrm{AC} \mathrm{Wh} / \mathrm{mi}$. The Chevrolet Volt has two modes of operation: (1) electric vehicle mode (EV) and (2) extended range mode (ERM). Over the entire data collection period, the AC electrical energy consumption when operating in $\mathrm{EV}$ mode was $358 \mathrm{AC} \mathrm{Wh} / \mathrm{mi}$ and the fuel economy when operating in ERM mode was $36.1 \mathrm{mpg}$. These fleet summary metrics are shown in graphical form in Figure 1.

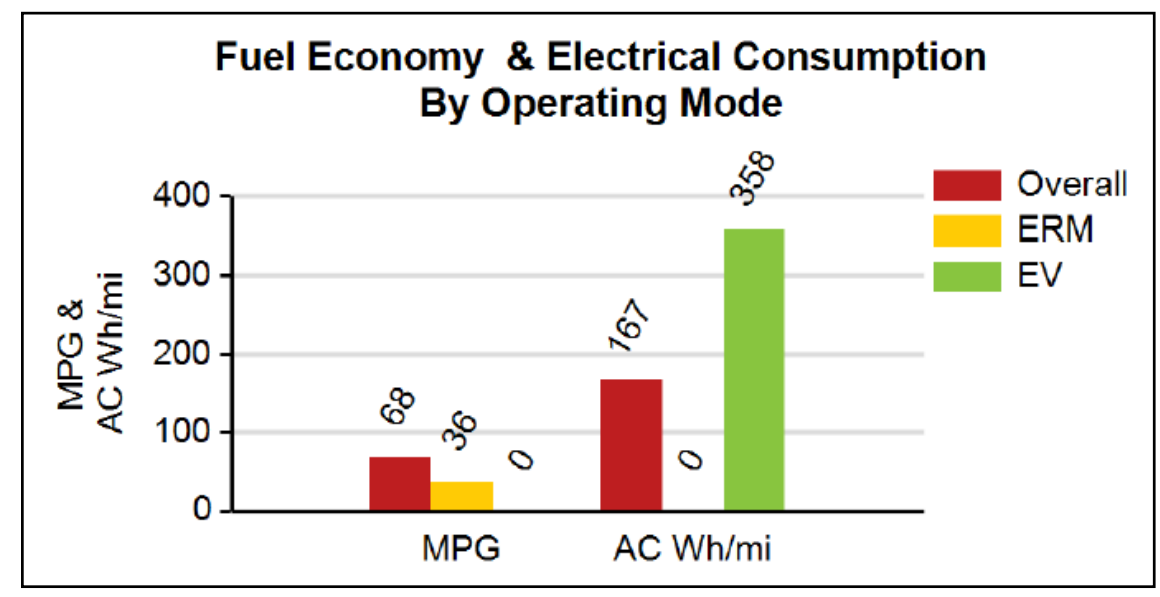

Figure 1. Overall fleet fuel economy and electrical energy consumption.

In order to better understand how the fleet of vehicles were operated given the two operating modes (i.e., EV and ERM), a histogram was created to help visualize the distribution of distance traveled in each operating mode for a given total trip distance. Figure 2 shows the percent of total distance traveled for both the EV and ERM modes of operation across various bins of trip distance for the entire fleet of 150 Chevrolet Volts over the data collection period. The majority of miles driven in EV mode are primarily in trip distances of less than 50 miles, with the largest percentage of total distance traveled during trips of 10 to 20 miles in length. Miles driven in ERM are more evenly distributed across all trip distances. The largest percentage of total distance traveled in ERM occurred for trip distances greater than or equal to 100 miles.

During real-world, on-road operation of the 150 Chevrolet Volts, the vehicles were used for a wide variety of purposes across a wide range of driving routes. These routes were characterized into two categories: (1) city routes and (2) highway routes. This was done in order to better understand and visualize vehicle utilization. Predominately, the city driving routes were lower average vehicle speed with multiple stops per mile, whereas the highway driving routes had a higher average speed with minimal stops per mile. Figure 3 shows the percent of total distance traveled for both city driving routes and highway driving routes for the entire fleet of 150 Chevrolet Volts for the entire data collection period. The 
majority of the city route trip distances were less than 30 miles. In contrast, the highway trips were more evenly distributed across trip distances of greater than 20 miles, except for trip distances greater than 100 miles, which is significantly the largest percentage of total distance traveled for highway driving routes.

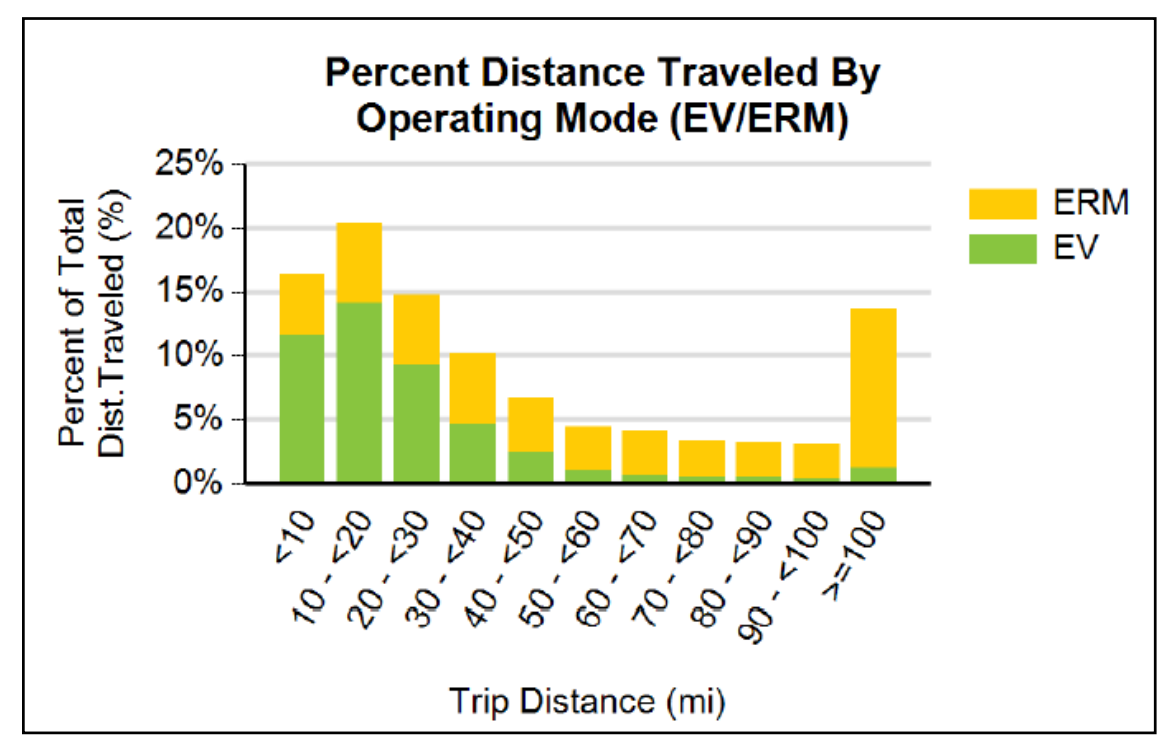

Figure 2. Percent distance traveled in each operating mode.

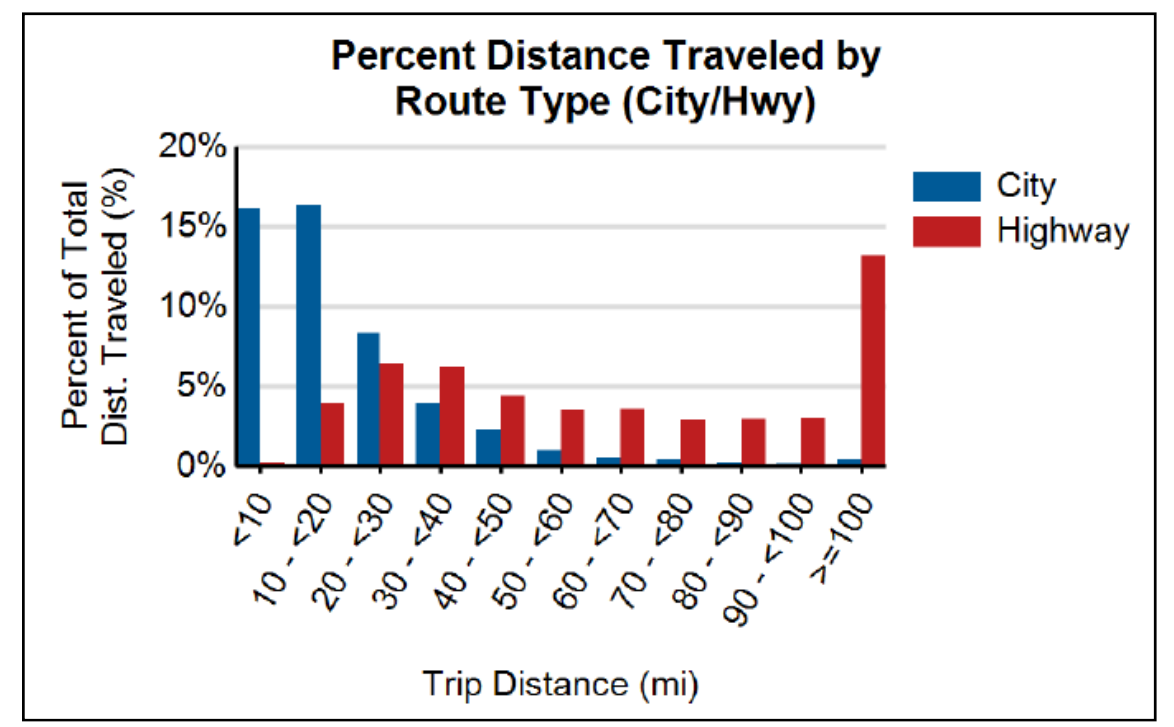

Figure 3. Percent distance traveled for city or highway route type.

During driving, the Chevrolet Volt calculates driving style efficiency based on many parameters (such as acceleration, vehicle speed, accessory utilization, and many more factors). This driving style efficiency impacts the electrical energy consumption and fuel economy of the vehicle. The higher the driving style efficiency, the better the fuel economy and electrical energy consumption. In order to understand and characterize the fleets' driving style efficiency in both EV mode and ERM, a histogram was created. Figure 4 shows the percent of total distance traveled versus driving style efficiency for both the EV mode and ERM for the entire fleet of 150 Chevrolet Volts for the entire data collection period. The average driving style efficiency for the EV mode and ERM are $78 \%$ and $77 \%$, respectively. The distribution for EV mode operation has a slightly wider spread than for ERM. Also, the mode (i.e., most 
frequent occurrence) for EV mode operation occurs between 90 and 100\% driving style efficiency, whereas the mode for ERM operation occurs between 80 and $90 \%$ driving style efficiency.

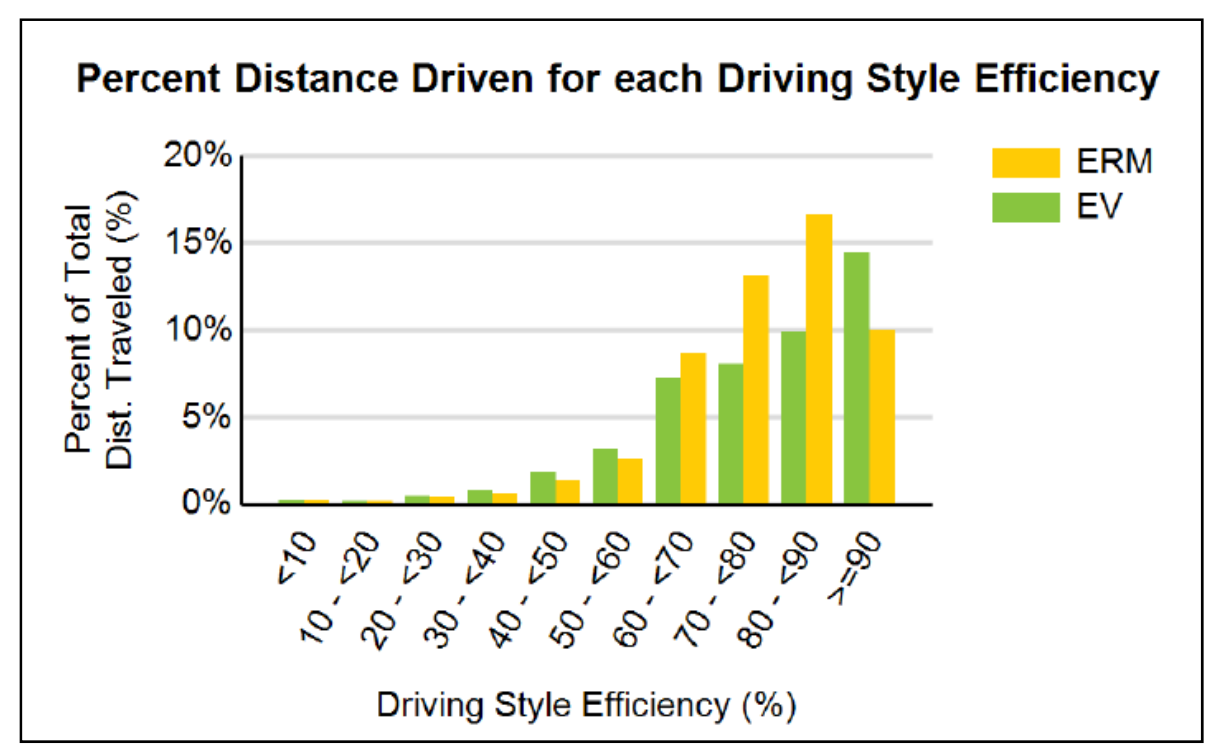

Figure 4. Percent distance traveled for each driving style efficiency.

For grid-connected vehicles, it is important to understand the driving patterns and the charging patterns. For the fleet of 150 Chevrolet Volts, the time of day when driving and charging occurred was analyzed and are shown in Figure 5 and Figure 6, respectively. Driving primarily occurred during the daytime, with a moderate increase between 6:00 and 8:00 a.m. and 3:00 and 5:00 p.m. local time. The time of day when charging occurs appears to correlate well to charging after the completion of driving. This can be seen by the increase in charge energy between 7:00 and 9:00 a.m. and 6:00 and 7:00 p.m. local time.



Figure 5. Percent distance traveled versus time of day when driving. 


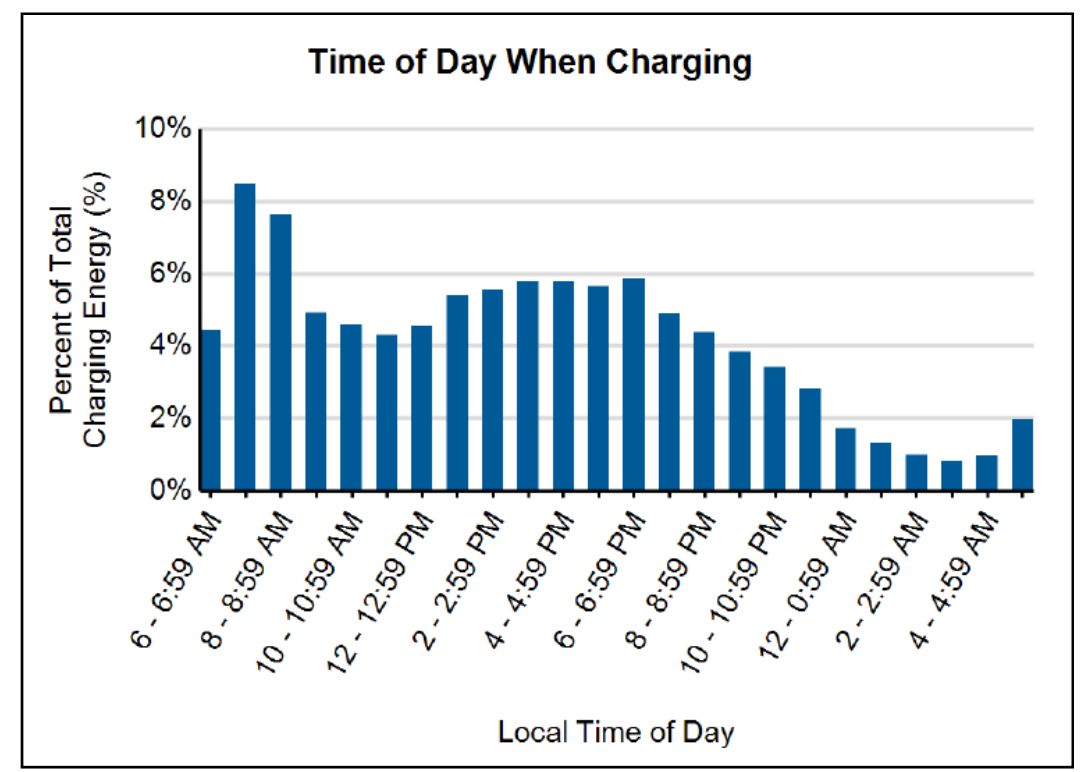

Figure 6. Percent of electrical energy delivered versus time of day when charging.

From the previously analyzed fleet operational characteristics of driving and charging and EV and ERM mode utilization, additional analysis was conducted on the battery pack state of charge with respect to the end of driving prior to plugging in and unplugging prior to driving. Figure 7 shows the state of charge of the battery pack at the end of driving prior to plugging in. Nearly half of these drive events end with a battery state of charge less than $10 \%$, which indicates there is little to no energy remaining on the battery pack. Figure 8 shows the state of charge of the battery pack at the end of charging prior to driving. Over $80 \%$ of these charge events end with a full battery pack (i.e., greater than or equal to $90 \%$ state of charge), which indicates that the vehicle will have the opportunity to maximize the EV driving miles because the energy stored in the battery pack is maximized.

Throughout the data collection period, additional analysis was conducted to determine other metrics (e.g., percent of total driving distance in EV mode and ERM and fleet average driving distance between charge events). Figure 9 shows the correlation between fleet average driving distance between charge events and percent of total distance traveled in EV mode over the duration of the data collection period. Near the beginning of the data collection period for the 150 Chevrolet Volts, the fleet average driving distance between charge events was less than 40 miles and the percent of total distance traveled in EV mode was greater than $50 \%$. As the demonstration progressed, driving and charging utilization of the vehicle changed slightly. By the end of the data collection period, the fleet average driving distance between charge events was greater than 50 miles and the percent of total distance traveled in EV mode was less than $40 \%$. This shows a correlation between the percent of total distance traveled in EV mode and the driving distance between charge events. Decreasing the fleet average driving distance between charge events can increase the percent of total distance traveled in EV mode, which inherently improves the fleet petroleum displacement by driving more electric miles.

The data collection period for the fleet of 150 Chevrolet Volts nearly covers two calendar years. This enabled analysis of the impact of seasonal ambient temperature variation on vehicle fuel economy and electrical energy consumption. Figure 10 shows the quarterly averaged ambient temperature impact, as averaged on a per vehicle basis, on electrical energy consumption ( $\mathrm{AC} \mathrm{Wh} / \mathrm{mi}$ ) when driving in $\mathrm{EV}$ mode and fuel economy (mpg) when driving in ERM mode. At colder fleet average ambient temperatures (i.e., less than $60^{\circ} \mathrm{F}$ ), there is a measurable trend that shows an increase in electrical energy consumption while driving in EV mode and a decrease in fuel economy when driving in ERM. For moderate 
temperatures (i.e., between 60 and $80^{\circ} \mathrm{F}$ ), there appears to be little to no impact of ambient temperature change on fuel economy or electrical energy consumption.

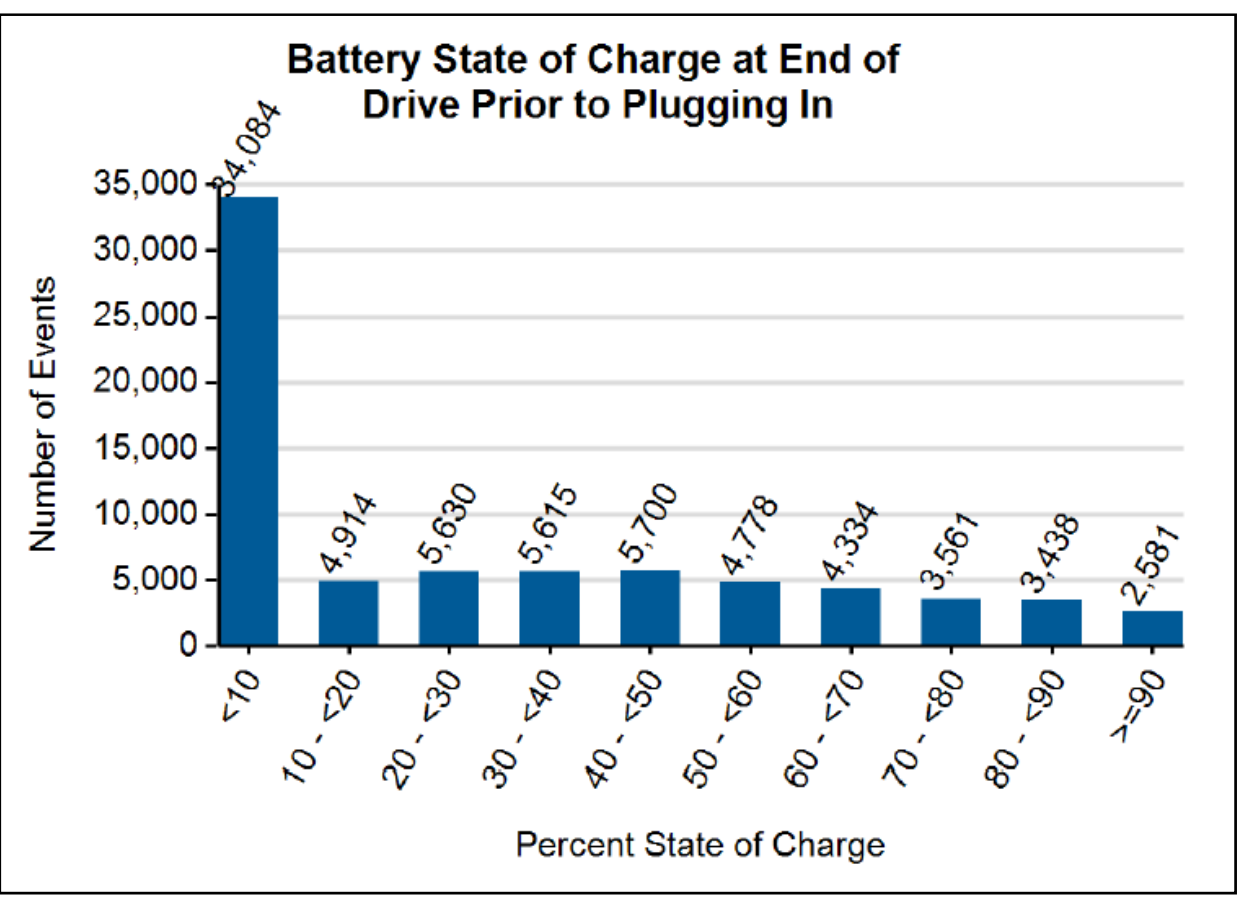

Figure 7. Distribution of battery state of charge at the end of driving prior to plugging in.

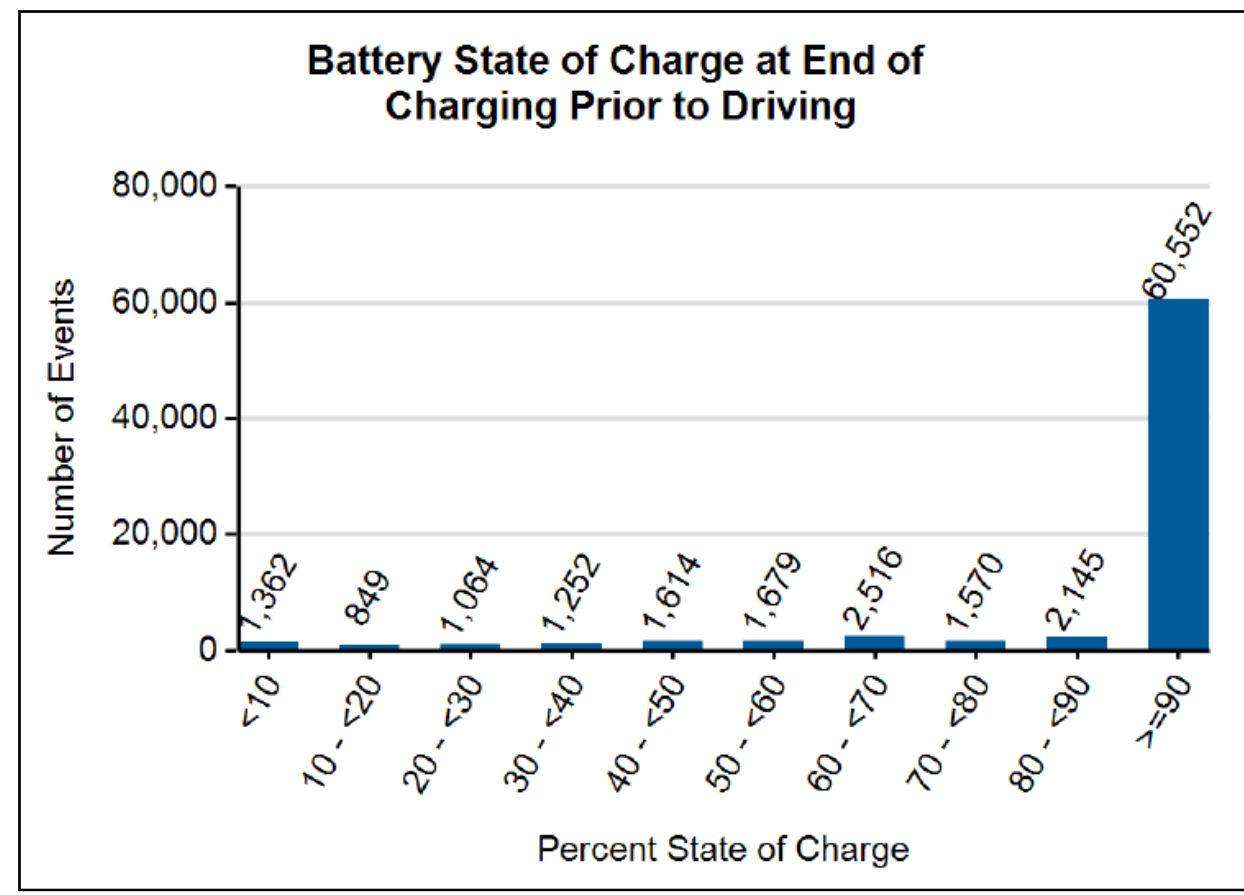

Figure 8. Distribution of battery state of charge at the end of charging prior to driving. 


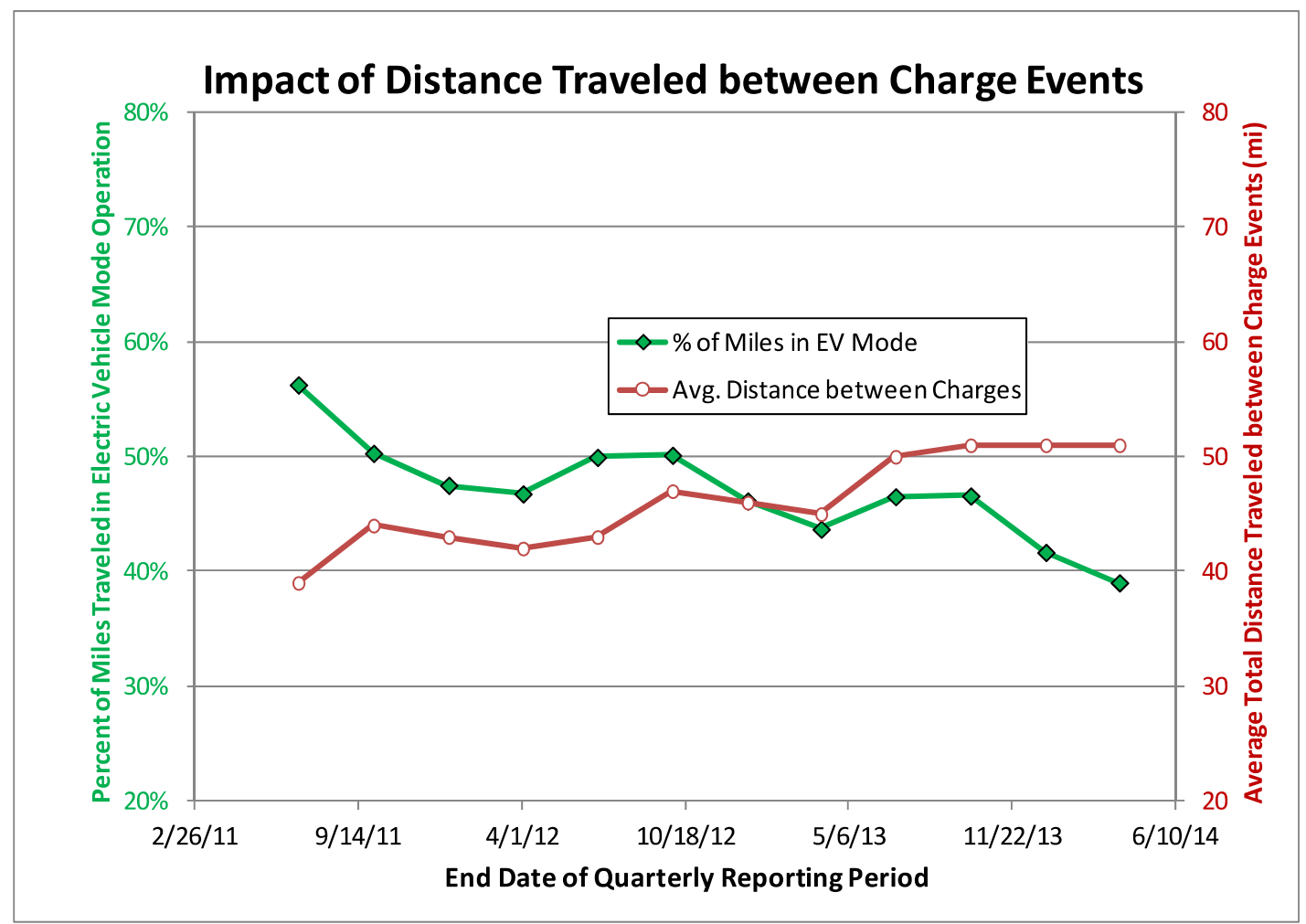

Figure 9. Impact of average distance driven between charge events on percent of total miles driven in electric vehicle mode.

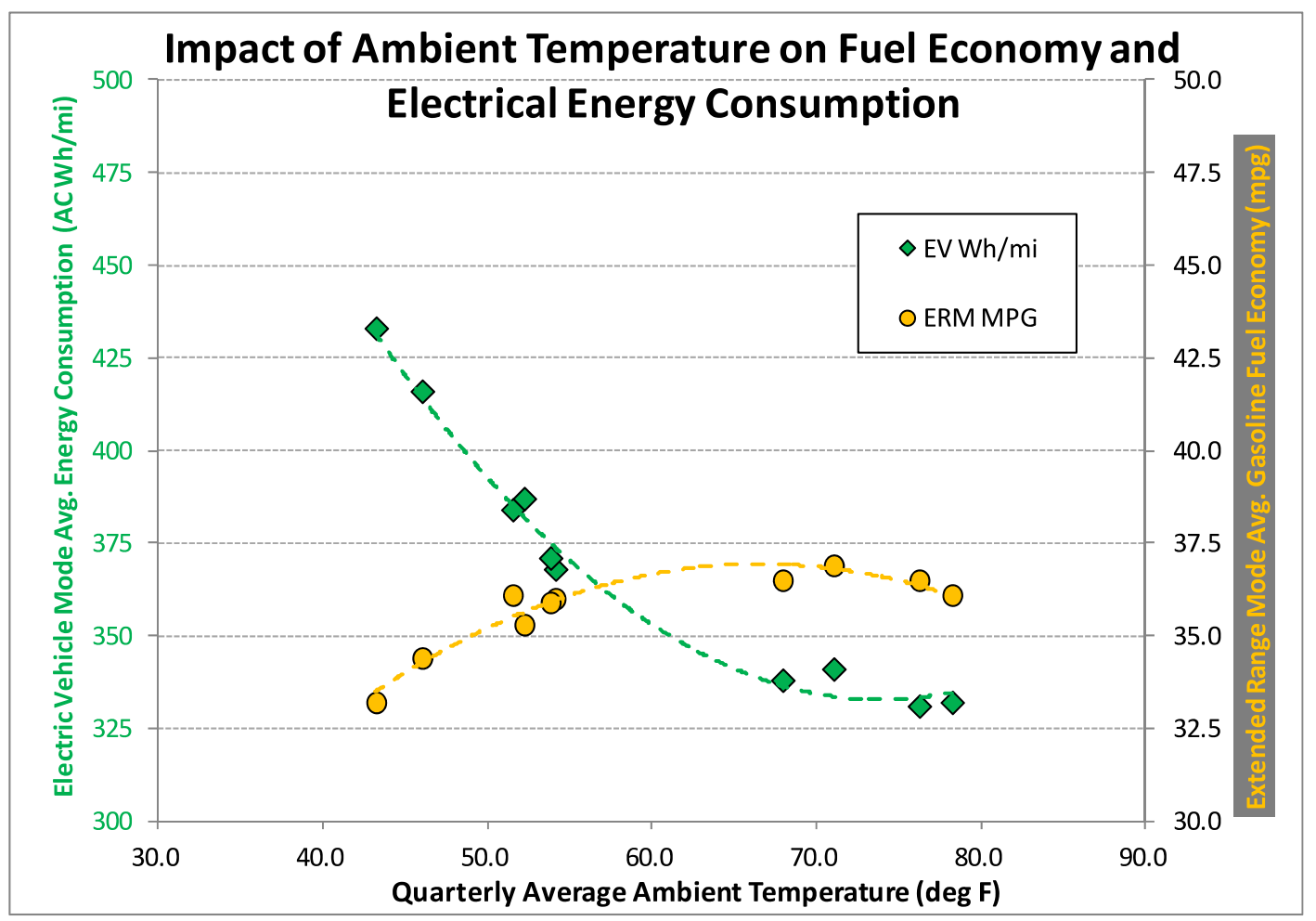

Figure 10. Impact of quarterly average ambient temperature on fuel economy in extended range mode and electrical energy consumption in electric vehicle mode. 
Idaho National Laboratory analyzed data from 150 Chevrolet Volts that were collected from May 2011 through March 2014 as part of the ARRA Vehicle Demonstration. Quarterly reports were published to http://avt.inel.gov/gmvehicledemo.shtml, which detailed the vehicle operational characteristics, fuel economy, electrical energy consumption, driving and charging utilization, driving style efficiency, and ambient temperature profiles. Over the period of data collection, the fleet of 150 Chevrolet Volts accumulated a total distance of 3.84 million miles over a total of 66,572 days of driving. Over the entire data collection period, the fleet average fuel economy was $67.5 \mathrm{mpg}$ and overall AC electrical energy consumption was $167 \mathrm{AC} \mathrm{Wh} / \mathrm{mi}$. Additional metrics were analyzed to characterize and visualize their impact on fuel economy and electrical energy consumption. These additional metrics include ambient temperature, driving style efficiency, EV and ERM mode operation, battery pack state-of-charge utilization, route type, and distance driven between charge events. 